\title{
EL OCASO DEL REINADO DE FELIPE II VISTO POR UN CONFIDENTE DE ARIAS MONTANO ${ }^{1}$
}

\author{
Baldomero MACÍAS ROSENDO \\ Universidad de Huelva
}

\begin{abstract}
RESUMEN: La decadencia que acompaña a los últimos años del reinado de Felipe II marcados por el hambre, las epidemias, la bancarrota, la mala administración y los desastres bélicos, tales como el asalto anglo-holandés a la ciudad de Cádiz en julio de 1596, que llevan a su punto más bajo el orgullo patrio, constituyen el objeto de la denuncia de Bartolomé Ruiz de Ávila, un confidente de Arias Montano que aprovecha la cercanía del biblista al poder para hacer llegar al rey el descontento por los abusos y mala gestión de las autoridades religiosas, civiles y militares. Son dos cartas en las que se traza un panorama desolador marcado por el desencanto y la frustración.
\end{abstract}

PALABRAS CLAVE: Felipe II, Arias Montano, Ruiz de Ávila, Cádiz, asalto anglo-holandés.

ABSTRACT: The decadence and decline which accompanied the final years of the reign of Philip II, overshadowed by hunger, epidemics, bankruptcy, bad administration and disastrous wars, such as the Anglo-Dutch assault on the city of Cadiz in July 1596, which brought national pride to its lowest ebb, were the object of the denunciation made by Bartolomé Ruiz de Ávila, a close collaborator of Arias Montano. Bartolomé Ruiz de Ávila took advantage of the latter's close links to power and government to make the king aware of the widespread discontent caused by the abuses and bad management of the religious, civil and military authorities. They are two letters in which a desolate panorama is outlined, marked by disenchantment and frustration.

KEYWORDS: Philip II, Arias Montano, Ruiz de Ávila, Cádiz, Anglo-Dutch assault.

La fama de Benito Arias Montano ${ }^{2}$ como persona influyente y muy próxima a Felipe II y al inmenso poder de la Monarquía Católica, en cuyos acontecimientos

${ }^{1}$ Recibido el 25 de marzo y aceptado para su publicación el 17 de septiembre de 2010.

${ }^{2}$ Para un acercamiento a la figura de Benito Arias Montano (Fregenal de la Sierra, 1527 - Sevilla, 1598) puede consultarse el repertorio bibliográfico de R. CASO AMADOR (2004-2005). «Bibliografía sobre el humanista Benito Arias Montano (1832-2005)». Etiópicas, 1, pp. 271-310. Dejando al margen los estudios y ediciones sobre su epistolario, que veremos más adelante, nos parecen especialmente interesantes los siguientes trabajos: T. GONZÁLEZ CARVAJAL (1832) «Elogio histórico del Doctor Benito Arias Montano». Memorias de la Real Academia de la Historia, t. VII, pp. 1-199. L. Morales Oliver (1927). Arias Montano y la política de Felipe II en Flandes. Madrid: Voluntad. B. ReKers (1973). Benito Arias Montano (1527-1598). Madrid: Taurus. G. Morocho Gayo (1998). «Trayectoria humanística de Benito Arias Montano I. Sus cuarenta primeros años (c. 1525/27-1567)». 
históricos se vio obligado en muchas ocasiones a inmiscuirse, explica que sus deudos y allegados acudan a él como intercesor para alcanzar dones y mercedes e incluso, como en el caso que aquí nos ocupa, recurran a su persona como el filtro adecuado para hacer llegar a instancias más altas las quejas y el descontento por los abusos de los ministros de Dios y del Rey: «Suplico a v[uestra] m[erced] ponga ese memorial en las manos de quien lo remedie, como lo a hecho de los demás que yo he enbiado, que puesta intercesión de los buenos puede mucho con Dios, tanbién podrá con los reyes; que no es posible que persuadiéndolo muchas vezes dexe de remediarlo» ${ }^{3}$.

Los últimos años del reinado de Felipe II fueron especialmente difíciles en Castilla y Andalucía. Durante varios años todo había marchado mal, y entre la población se había extendido un sentimiento de insatisfacción generalizada. En muchos lugares de Andalucía escaseaban los alimentos a causa de la sequía y la pérdida de cosechas ${ }^{4}$. Se dieron algunos brotes de pequeñas epidemias que desembocaron en la peste bubónica que asoló el corazón de la península a partir de 1596. Alrededor de 1595 una tercera parte de las tierras de labor había dejado de

En Marqués De la Encomienda y otros (eds). El humanismo extremeño. Segundas Jornadas. Trujillo: Real Academia de Extremadura de las Letras y las Artes, pp. 157-210. G. MoRocho GAYO (1999). «Trayectoria humanística de Benito Arias Montano II. Años de plenitud (1568-1598)». El humanismo extremeño. Terceras Jornadas. Trujillo: Real Academia de Extremadura de las Letras y las Artes, pp. 227-304. G. Morocho GAYO. (1998). "Avance de datos para un inventario de las obras y escritos de Arias Montano». La Ciudad de Dios, CCXI, núm. 1, pp. 179-275. J. GIL (1998). Arias Montano en su entorno. [Bienes y herederos]. Mérida: Editora Regional de Extremadura. V. BÉCARES Botas (1999). Arias Montano y Plantino. El libro flamenco en la España de Felipe II, León: Secretariado de Publicaciones de la Universidad de León. L. Gómez CANSECo (ed, 1998). Anatomía del Humanismo. Benito Arias Montano 1598-1998. Actas del Simposio Internacional celebrado en la Universidad de Huelva, Huelva: Diputación Provincial de Huelva-Universidad de Huelva. J.M. MAestre Maestre y otros (eds, 2006). Benito Arias Montano y los humanistas de su tiempo. Mérida: Editora Regional de Extremadura. Además de los números monográficos dedicados a Montano en Revista Española de Estudios Bíblicos, 1928; Revista de Estudios Extremeños, 1928 y 1996; Cuadernos de Pensamiento, $\mathrm{n}^{\circ}$ 12, Madrid: FUE, 1998; los estudios presentados a las cuatro Jornadas organizadas por la Real Academia de Extremadura de las Letras y las Artes entre 1996 y 2000, publicados bajo el título El humanismo extremeño. Asimismo aportan abundante información los estudios preliminares de las numerosas ediciones de obras de Arias Montano publicadas en la colección "Bibliotheca Montaniana" del Servicio de Publicaciones de la Universidad de Huelva y de la colección "Humanistas Españoles" del Secretariado de Publicaciones de la Universidad de León.

${ }^{3}$ Véase más abajo la carta de Bartolomé Ruiz de Ávila fechada a 8 de junio de 1595.

${ }^{4}$ En Sevilla hubo, al menos, dos grandes hambrunas: una en 1557 y otra entre 1596 y 1602 , esta última afectó a todo el reino, causando enormes daños en la población sevillana. D. ORTIZ DE ZÚÑIGA (1988, ed. facsímil de 1796). Anales eclesiásticos y seculares de la muy noble y muy leal ciudad de Sevilla. Sevilla: Guadalquivir, t. IV, pp. 6-7. A. DomínGUEZ ORTIZ (1992). La sociedad española en el siglo XVII. Granada: Universidad de Granada, pp. 69-70. 
cultivarse. Los labradores cada vez más acosados por las deudas se veían despojados de sus tierras por los acreedores. De esta suerte una gran parte del suelo cultivable pasaba a manos de los latifundistas, mientras que muchos labradores abandonaban sus campos y marchaban a los centros urbanos para ganarse el sustento mendigando. Paralelamente al abandono de las tierras y al aumento de los dominios señoriales, se produjo un aumento de los precios, situación que se vio agravada por la sequía y la pérdida de las cosechas hasta convertirse en una auténtica catástrofe: «De muchos años a esta parte -observaba un alto funcionariola esterilidad de los tiempos ha sido tanta que se han padecido hambres y trabajos por falta de pan» ${ }^{5}$. Y Mateo Alemán escribía en su Guzmán de Alfarache: «Era el año estéril de seco, y en aquellos tiempos solía Sevilla padecer, que aun en los prósperos pasaba trabajosamente: ¡mirad lo que sería en los adversos! No me está bien ahondar en esto ni decir el porqué. Soy hijo de aquella ciudad: quiero callar, que todo el mundo es uno, todo corre unas parejas, ninguno compra regimiento con otra intención que para granjería, ya sea pública o secreta; pocos arrojan tantos millares de ducados para hacer bien a los pobres, antes a sí mismos, pues, para dar medio cuarto de limosna, la examinan» ${ }^{6}$.

A la carestía de alimentos se sumó desde 1590 una excesiva carga impositiva sobre los alimentos de primera necesidad por la creación de «los millones», un nuevo impuesto que gravaba la carne, el vino, el aceite y el vinagre, y que recaía directamente sobre los más desheredados. Ello ocasionó protestas generalizadas y conatos de motines demandando su abolición. La situación respecto a estos abusos había de ser lo suficientemente grave como para que el licenciado Francisco Porras de la Cámara se dirigiera al arzobispo de Sevilla a principios del XVII asegurando que «la mercería y el trato se ha convertido en robo y en regatonería, estancando todos los géneros, desde el oro y seda hasta las legumbres, para revenderlas excesivamente cuando, por haberlas ellos atravesado, está falta la plaza. Y lo peor es que son deste trato los que habían de remediarlo, porque es tal el humano interés, que todo lo atropella» ${ }^{7}$. De una fecha próxima, como 1621 , se conserva en el Archivo Histórico Nacional un informe que los Jurados de Sevilla enviaron al rey en el que se traza un panorama similar: «La gente pobre en esta ciudad come

\footnotetext{
${ }^{5}$ J. Castillo De Bobadilla (1597). Política para corregidores..., Madrid: Sánchez, parte II, p. 38.

${ }^{6}$ Mateo Alemán, Guzmán de Alfarache. Edición de J. Ma Micó (1989). Madrid: Cátedra, pp. 169-170.

7 A. PaZ y Meliá (1900). «Memorial del Licenciado Porras de la Cámara al Arzobispo de Sevilla sobre el mal gobierno y corrupción de costumbres en aquella ciudad». Revista de Archivos, Bibliotecas y Museos, IV, p. 553.
} 
los mantenimientos más caros que en otra parte del reino, por el mal gobierno della y estar todos los tratos en poder de regatones, que por ser favorecidos de jueces superiores y personas poderosas, así de la audiencia como del regimiento y fieles ejecutores y otros, no se castigan los excesos que en esto hay y redunda todo en perjuicio de los pobres, que primero que llegan los mantenimientos al consumo han pasado por tres o cuatro manos de regatones, que, fiados en el favor de sus valedores por los regalos que les hacen, no guardan postura en otra cosa alguna». Entre otros, los jurados llegan a culpar de la situación a los regidores sevillanos: «Los Veinte y cuatros de esta Ciudad no cumplen con sus obligaciones, pues, teniéndolas de mirar por el bien desta República y por el Gobierno della, por sus pasiones particulares, a que sólo tienden, se olvidan de lo demás que conviene al bien público, y así se halla esta República en un miserable estado, así de carestía en los mantenimientos como en imposibilidad de poder andar por las calles, por estar desempedradas y tan llenas de inmundicias y que se pueden temer grandes y graves enfermedades» ${ }^{8}$.

No muy diferente es el panorama de corrupción generalizada que denuncia el confidente de Arias Montano: «se hazen grandes robos en aquellos tribunales del provisor y juez de la Yglesia, [...] las hordenaças y premáticas que aý van apuntadas no sirven de más que de tronpeçones para que los juezes y sus ministros hagan causas y lleven penas a muchos sin aver cometido culpas. [...] Véndese por dineros lo que se deve dar gratis, y dasse mal despacho a los negociantes por sacarles dineros y más y más costas. [...] Vende el Arçob[is]po los alguaziles de los lugares y les da facultad para que denuncien y prendan los que quebrantan las fiestas. [...] Que los juezes ecclesiásticos y seglares se encuentran en causas y las sentencian y condennan por ambas partes»»?

De la mano del hambre llegaron las epidemias que diezmaron las pobladas ciudades castellanas, adonde acudía la grey desnutrida de los desamparados, causando estragos entre pobres y mendigos. El rey, consciente del malestar creciente entre sus súbditos, hacía tiempo que no se encontraba bien de salud y hacía grandes esfuerzos por mantenerse al frente del gobierno. Por tanto, aunque las decisiones siguieron siendo suyas, la dirección efectiva era de Cristóbal de Moura y Juan de Idiáquez, el primero se ocupaba de la política interior; mientras que Idiáquez se encargaba de todos los asuntos exteriores. Sin embargo, como su

${ }^{8}$ «Informe de los Jurados de Sevilla a Felipe IV sobre materias de gobierno que deben reformarse en aquella ciudad. Documentos procedentes del Archivo Histórico Nacional y del Archivo de Simancas: 1618-1625». Archivo Histórico Español. Valladolid, 1932, pp. 148 y 190-191.

${ }^{9}$ Carta de Bartolomé Ruiz de Ávila para B. Arias Montano fechada a 8 de junio de 1595. 
malestar, lejos de aliviarse, se agravaba, Felipe aceptó delegar algunos de sus poderes en manos del príncipe. En mayo de 1595 la salud regia empeoró repentinamente. En la administración del Estado se palpaba la intranquilidad general: en la corte había poca confianza en la persona del príncipe.

Para colmo de los males, el orgullo nacional estaba por los suelos. La guerra, responsable en gran medida de la difícil situación económica, daba pocas alegrías. El desastre de la Armada Invencible socavó seriamente la confianza depositada en el Rey. Se desvanecía con rapidez el triunfalismo de principios de los ochenta sustentado por la rápida y exitosa ocupación de Portugal. Los ingleses campaban a sus anchas y asolaban el litoral de la península ibérica sin encontrar la más mínima resistencia, perpetrando una sucesión de acciones tácticas y de castigo contra los intereses españoles: ya en 1585 habían atacado puntos neurálgicos de las Indias en Santo Domingo y en Cartagena; el 29 de abril de 1587 Francis Drake invadió por sorpresa el puerto de Cádiz con una flota de 23 navíos, situación que se vio agravada tras el desastre de la Armada Invencible y el consiguiente deterioro de la marina española. Todo ello favorecería la propuesta del conde de Essex de atacar España. El 30 de junio de 1596 una poderosa flota anglo-holandesa integrada por 128 velas, al mando de Sir Charles Howard de Effingham, luego conde de Nothinghan, que ya se había distinguido por su actuación contra la Armada Invencible, apareció frente a Cádiz: la flota llevaba a bordo a 6.500 soldados ingleses bajo las órdenes del conde de Essex y a un millar de holandeses bajo la autoridad del almirante Johan van Duivenvoorde.

Durante la mañana del primero de julio la flota enemiga se abrió pasó con fuego de artillería entre las fuerzas navales que defendían la bahía ${ }^{10}$. A mediodía, el conde de Essex embarcó a toda prisa en lanchas a unos 3.000 hombres de las compañías de tierra y los desembarcó en una pequeña ensenada cerca de Puntales. Y desde allí una parte del contingente marchó hacia la isla de León con objeto de impedir el auxilio a Cádiz desde tierra firme. Con el resto de fuerzas y las que sucesivamente iban desembarcando, el conde de Essex atacó la ciudad tras hacerse

${ }^{10}$ Véase M. Bustos RodríGUEz (1997). El asalto anglo-holandés a Cádiz en 1596 y su contexto internacional. Cádiz: Servicio de Publicaciones de la Universidad de Cádiz. FrAY PEDRO DE ABREU Historia del saqueo de Cádiz por los ingleses en 1596. Edición de M. Bustos (1996). Cádiz: Servicio de Publicaciones de la Universidad de Cádiz. M. Fernández de NAVArRete, - M. SAlvá (1860). Documentos inéditos para la Historia de España. Madrid: Imprenta de la viuda de Calero, vol. 36. La relación del canónigo Francisco de Quesada, titulada Relación de lo sucedido en Cádiz desde veynte y nueve de junio de 1596 hasta catorce de julio, puede verse en J.I. TELLECHEA IDÍGORAS (1996). «El asalto inglés a Cádiz». Historia 16, n 248, pp. 31-46. 
con el control de la Puerta del Muro (actual Puerta Tierra). Los atacantes encontraron fuerte resistencia en las calles y en la plaza del mercado.

Al día siguiente, 2 de julio, por la mañana, las fuerzas defensoras y los refugiados en el castillo de la villa izaron bandera blanca, y tras parlamentar con el conde de Essex acordaron rendirse y pagar 120.000 ducados como rescate. Los ingleses se comprometieron a facilitar el embarque de mujeres y religiosos para pasar al Puerto de Santa María, consintiendo que la gente más humilde marchara conducida por tierra hasta el puente de Suazo. El conde de Essex dio muestras de gran caballerosidad no sólo por este gesto que a todos sorprendió, sino manteniendo constantemente a raya a sus hombres y prohibiéndoles entrar en las casas para cometer desmanes.

El grueso de la flota de Indias, que había escapado de los ingleses, refugiándose en las cercanías de Puerto Real, fue incendiado por orden del almirante de la flota. En total, unas 57 velas, entre buques de guerra y mercantes, fueron pasto de las llamas, así como un rico cargamento valorado en unos 12 millones de ducados.

Tras dos semanas de ocupación, el día 14 de julio el mando inglés dio orden de reembarcar a los distintos regimientos, pues desde toda Andalucía ya acudían tropas reclutadas para la liberación de Cádiz en un número muy superior a las fuerzas ocupantes. Apenas iniciado el reembarque, se incendió la ciudad por diversos puntos y no cesó de arder hasta que los asaltantes la perdieron de vista el día 17 de julio.

La operación se saldó con una rotunda victoria naval de la armada angloholandesa en el puerto de Cádiz y posterior asalto a la ciudad, que por espacio de dos semanas quedó bajo control de las fuerzas asaltantes, objetivos que se lograron con un mínimo de bajas. La ciudad, humillada y saqueada, fue pasto de las llamas y sus habitantes tuvieron que salir precipitadamente de ella. Algunas personas de calidad quedaron como rehenes en Inglaterra hasta entrado el siglo XVII y fue preciso pagar una abultada suma en concepto de rescate. Las milicias urbanas, de quienes dependía en buena parte la defensa, fueron incapaces de reaccionar adecuadamente; tampoco lo hicieron las tropas de las poblaciones circundantes, puestas bajo el mando del discutido duque de Medina Sidonia.

Cádiz era el principal puerto español del comercio con América, símbolo del poderío marítimo de España, por lo que ingleses y holandeses identificaban a este puerto con el centro neurálgico del monopolio colonial ibérico. Sabían que las flotas que periódicamente salían de la bahía de Cádiz eran las encargadas de transportar los tesoros procedentes de América, que la Monarquía Católica esperaba con impaciencia para calmar las angustias económicas provocadas por la 
guerra en Flandes. Atacar la ciudad de Cádiz era hacerse al mismo tiempo con los barcos españoles y asfixiar aún más la insostenible situación económica de las arcas reales, ya que supuso la paralización del tráfico de la flota de Indias durante todo un año.

El efecto moral del ataque a Cádiz fue demoledor y ello explica las amargas palabras de escritos como el que Ruiz de Ávila remite a Montano, quien achaca el desastre al mal gobierno y a la corrupción: «que todo ande a ciegas y que no se vea este abismo de adonde salen siempre n[uest]ros daños; los quales van cada día en tanto crecimiento que por governarse los que estavan en Cadis por cabeças que quieren ser universales en todo, no siendo particulares en su facultad, se perdió y se perderá todo el mundo, si Su Mag[esta]d no pone ministros de esperiencia que lo defiendan. [...] Ni tanpoco se deve aconcejar a Su Mag[esta]d que ponga estanco en la pólvora y demás municiones por cudicia de quatro reales, [...] porque de aver estanco viene a estar falto de municiones este reyno, y a ponerse en condición de perder una buena parte de esta Andaluzía. [...] Y las galeras que eran las que otras vezes nos defendían y con quien se amenazava a todos los cosarios que nos venían a robar, es aora la peor cosa que tiene el mundo y de más costa y menos provecho; porque dies y nueve que se hallaron en lo de Cadis y estuvieron a la mira hasta que el inglés se fue, no hizieron cosa que fuese de consideración, porque ni traen municiones ni remeros ni soldados» ${ }^{11}$.

El que la ciudad de Cádiz hubiera sido ocupada sin impedimento durante dos semanas representó un serio golpe al prestigio español. Esta humillación fue el punto más bajo en el hundimiento del honor y la reputación de España. También escritores de renombre se hicieron eco de la triste sensación de fracaso e impotencia que el hecho causó en toda las esferas, convirtiendo al duque de Medina Sidonia, a quien se culpó de la tardanza en acudir al socorro de Cádiz, en el blanco de todas las burlas. En este sentido es muy conocido el soneto $A$ la venida del inglés a Cádiz, atribuido a Cervantes ${ }^{12}$ :

Vimos en julio otra Semana Santa atestada de ciertas cofradias que los soldados llaman compañias de quien el vulgo y no el inglés se espanta.

Hubo de plumas muchedumbre tanta que en menos de catorce o quince dias

${ }^{11}$ Carta de Bartolomé Ruiz de Ávila para Arias Montano fechada a 31 de julio de 1596.

12 Sobre la mala relación de Cervantes con el duque de Medina Sidonia, véase L. OsTREC (1993). La verdad sobre las Novelas ejemplares. México: UNAM, pp. 342-343. 


\begin{abstract}
volaron sus pigmeos y Golías
y cayó su edificio por la planta.

Bramó el becerro y púsolos en sarta,

tronó la tierra, escureciose el cielo

amenazando una total ruina...

y al cabo en Cádiz, con mesura harta,

ido ya el conde, sin ningún recelo,

triunfando entró el gran duque de Medina ${ }^{13}$.
\end{abstract}

Sobre el mismo asunto escribió otro soneto, que lleva por título El saco de Cádiz, Juan Sáez de Zumeta, agudo poeta sevillano celebrado por Cervantes en el canto de Calíope de La Galatea, quien en el verso final alude al duque de Medina como "dios de los atunes", por alusión a ser dueño de la almadraba de Zahara de los Atunes, ya que el atún, a pesar de su tamaño, es tímido y cobarde:
¿De qué sirve la gala y gentileza, las bandas, los penachos matizados, los forros rojos, verdes y leonados, si pide armas el tiempo con presteza?
Cuando lleva robada la riqueza de Cádiz el Britano, y profanados deja templos y altares consagrados: Eterna infamia, oh España, a tu grandeza; cuando el amigo llora del amigo los daños, y lloramos las deshonras de nuestra lealtad amargamente; cuando en desprecio nuestro el enemigo con palabras ensalza nuestras honras, iy el dios de los atunes lo consiente! $!^{14}$

Estrechamente vinculado con ese hostigamiento hacia los intereses españoles, y pese a que a la hora de lanzar la ofensiva la reina Isabel primara las razones puramente comerciales sobre su simpatía hacia los rebeldes holandeses o la afinidad de credo, estaba el problema de la guerra de Flandes, el eje sobre el que gira toda la política exterior de Felipe II y el auténtico cáncer de la Monarquía Católica. Tras una lucha de más de treinta años, que ni la intervención armada del duque de Alba ni la política pacifista de Requesens habían sabido solucionar, la opinión pública piensa que la guerra ha ido demasiado lejos y que es preciso

${ }^{13}$ F. Sevilla Arroyo - A. Rey Hazas (1993). Miguel de Cervantes, Obra completa. Alcalá de Henares: Centro de Estudios Cervantinos, III, p. 1408.

14 Texto tomado de J.A. Pellicer (1827). Trabajos de Persiles y Sigismunda. Nueva York: Lanuza, Medía y C., I, p. XXVII. 
buscarle una solución como sea. Los procuradores en Cortes protestan enérgicamente cuando se les piden más recursos para una guerra que cada vez menos gente siente como propia, a pesar incluso de la colaboración holandesa en el asalto de Cádiz de 1596. Al gran periodo de victorias de Alejandro Farnesio en los Países Bajos siguió uno de parálisis total. El Rey le había retirado su confianza al general, a quien culpaba en buena medida del desastre de la Armada Invencible. En agosto de 1589 tuvo lugar el primero de una sucesión de graves motines en el ejército español por falta de pagas. El duque de Parma había intentado convencer al gobierno español de que llegase a un arreglo con las provincias rebeldes basado en concesiones religiosas. Los ministros convinieron en que reconquistar a las provincias separatistas ya no era el objetivo, y que seguir usando la fuerza sería perpetuar una guerra para la que no había ejército ni hacienda disponibles. Pese a estar de acuerdo, el Rey no tomaría ninguna decisión sobre el asunto sin antes consultar con Roma, y mientras se esperaba a que el Papa estudiase el problema, la guerra continuaba, sepultando en los pantanos de Flandes un capital humano y económico que Castilla ya no podrá soportar por más tiempo. A partir de 1589 el conflicto se agrava con la muerte de Enrique III de Francia, que formalmente convertía en su heredero al protestante Enrique de Navarra. Inmediatamente Felipe II, quien deseaba que el trono francés fuera ocupado por su hija Isabel Clara Eugenia, nieta de Enrique II de Francia, ordena a Farnesio avanzar hacia París y meterse en una guerra que se prolongará durante casi una década. Los gobernadores españoles en Flandes, obligados a sostener el frente holandés y el francés, a duras penas pueden abarcar ambos escenarios de batalla. Las Provincias Unidas aprovecharon esa ocasión para incrementar su territorio y zafarse definitivamente de la amenaza española. El Rey fracasó en su ambición y Enrique de Navarra fue coronado finalmente como rey de Francia en 1594 tras convertirse al catolicismo. Se estimaba, según los balances de 1594-1596, que el gasto derivado de la sublevación de los Países Bajos y la intervención en Francia consumía unos cuatro millones de ducados anuales. La difícil situación de la Hacienda real y del ejército español en los Países Bajos, falto de pagas y de mandos con prestigio, además de la necesidad de asentar políticamente las provincias leales a la corona, inducen al Rey a tomar finalmente la decisión de casar al archiduque Alberto de Austria con su hija Isabel Clara Eugenia y cederles los Países Bajos Católicos para así mantenerlos en la órbita hispana.

Desde Italia escribía el gobernador de Milán, Juan Fernández de Velasco, informando al rey de que «hay un deseo general en Italia de expulsar a los españoles ${ }^{15}$. En Portugal la resistencia se afianzaba en las esperanzas del regreso

${ }^{15}$ H. KAMEN (1997). Felipe de España. Madrid: Siglo XXI, p. 328. 
del rey don Sebastián, cuyo cadáver no había sido claramente identificado en el campo de batalla de Alcazarquivir. Entre los portugueses la leyenda popular se negaba a creer que los restos enterrados en Lisboa en 1582, en presencia de Felipe II, fueran los del rey. El mito del regreso de su rey mantuvo vivas las esperanzas de los partidarios de Antonio de Crato.

En resumen, se tiene la percepción que España se bate en retirada de todos los frentes. Si a ello se suma la prolongada enfermedad del rey, que paraliza la administración del Estado, los problemas económicos, consecuencia directa de la política belicista, y que acarrean la suspensión de pago a los acreedores en noviembre de 1596, los crecientes impuestos, la pérdida de cosechas de cereales, la carestía de los alimentos básicos, todo ello sirvió para alimentar el sentimiento de insatisfacción general que ha quedado patente en numerosos testimonios de la época, como las dos misivas que aquí recogemos de Bartolomé Ruiz de Ávila.

Prácticamente no sabemos nada de este personaje, que entre 1594 y 1618 aparece como párroco en el archivo de la Iglesia de Santiago el Mayor de Hinojos, pequeña localidad de la provincia de Huelva, a unos cuarenta y dos kilómetros de Sevilla, a cuya diócesis perteneció hasta la segregación canónica en 1953 de la diócesis onubense. La diferencia de edad con Arias Montano (1527-1598) excluye la hipótesis de un posible compañero de estudios, sino que más bien nos inclinamos a creer que se trate de un clérigo sin influencias (él mismo lamenta no poder asistir de ordinario en Sevilla) que busca el amparo del frexnense. De hecho, en la vasta correspondencia de Arias Montano ${ }^{16}$ no aparece ninguna otra mención a este

${ }^{16}$ A falta aún de una edición completa del epistolario montaniano, son fundamentales para su estudio, además de las numerosas cartas publicadas en un rosario de artículos, los siguientes trabajos: «Correspondencia del Doctor Arias Montano con Felipe II, el secretario Zayas y otros sugetos, desde 1568 hasta 1580». En MARQueSeS DE PIDAL y DE Miraflores (eds). Colección de documentos inéditos para la historia de España (CODOIN). Madrid: Imprenta de la viuda de Calero, 1862, volumen XLI, pp. 127-418. B. Macías Rosendo (1998). La Biblia Políglota de Amberes en la correspondencia de Benito Arias Montano (Ms. Estoc. A 902). Huelva: Servicio de Publicaciones de la Universidad de Huelva. J.I. Tellechea Idígoras (1998). «Benito Arias Montano y San Carlos Borromeo». En L. Gómez CANSECo (ed). Anatomía del Humanismo. Benito Arias Montano 15981998. Actas del Simposio Internacional celebrado en la Universidad de Huelva, Huelva: Diputación Provincial de Huelva-Universidad de Huelva, pp. 63-84. A. DÁvila PÉREZ (2002). Benito Arias Montano. Correspondencia conservada en el Museo Plantin-Moretus de Amberes, Alcañiz-Madrid: Laberinto. E. Morales Lara (2002). «Las cartas de Benito Arias Montano a Abraham Ortels: edición crítica y traducción al español». Humanistica Lovaniensia, LI, pp. 153-205. L. CHARLo BREA (2007). Levino Torrencio. Correspondencia con Benito Arias Montano. Alcañiz-Madrid: Instituto de Estudios Humanísticos-CSIC. B. Macías Rosendo (2008). La correspondencia de Benito Arias Montano con el Presidente de Indias Juan de Ovando. Huelva: Servicio de Publicaciones de la Universidad de Huelva. Además resulta especialmente útil el inventario de cartas localizadas que 
corresponsal, de quien sólo se han conservado las dos cartas que ahora presentamos, aunque se infiere por su propio testimonio que no son los únicos escritos que le remite a don Benito: «por parecerme que tampoco an de tener enmienda los daños presentes como la an tenido los passados de que he advertido» ${ }^{17}$.

Ambas cartas se han conservado al final del manuscrito A 902 de la Biblioteca Real (Kungliga Biblioteket) de Estocolmo, antiguo número 20 de la colección Sparwenfeld ${ }^{18}$, formado por una recopilación de ciento diecisiete documentos originales, en varias lenguas, y concernientes en su mayoría a la preparación de la Biblia Políglota Regia, trabajo que nuestro biblista coordinó y dirigió entre 1568 y 1573 en la ciudad de Amberes por encargo de Felipe II. La primera de las cartas que ahora presentamos iba además acompañada de un memorial («y de todo lo más del memorial que va con esto») que no ha llegado hasta nosotros, seguramente porque el propio Arias Montano le daría traslado al original hacia otras instancias, tal y como se lo pide Ruiz de Ávila: «Suplico a v[uestra] m[erced] ponga ese memorial en las manos de quien lo remedie, como lo a hecho de los demás que yo he enbiado, [...] que primero tomarán mis papeles puerto en las manos de v[uestra] $\mathrm{m}$ [erced], para que los correga, que pasen adelante donde se pierdan y no se reciban con tan buena voluntad como se escriven y se enbían ${ }^{19}$. No obstante, podemos hacernos una idea bastante aproximada de su contenido gracias a las anotaciones que Montano nos ha dejado de su propio puño, en las que recoge los puntos más relevantes de un informe en el que su confidente se despacha con total libertad, arremetiendo contra los frecuentes abusos de las autoridades religiosas y seculares que actúan de espaldas a la corona. Pues este género de informes, aunque pueda sorprendernos, a menudo eran solicitados por el propio monarca o por sus ministros más próximos para tomar el pulso de la administración del Estado; y en este sentido tenemos constancia de que la opinión de Montano, y su red de informadores, requerida sobre los asuntos más diversos durante toda la segunda mitad del siglo XVI, fue siempre muy bien valorada por Felipe II. Baste recordar la correspondencia que mantiene desde Amberes con el

ofrece A. DÁvila PÉREZ (2002). «El epistolario de Benito Arias Montano. Catálogo provisional». De Gulden Passer, 80, pp. 63-129.

${ }^{17}$ B. Ruiz de Ávila a B. Arias Montano, a 8 de junio de 1595.

18 Para más detalles sobre el contenido de este manuscrito y su historia hasta terminar en tierras escandinavas puede consultarse nuestro estudio, ya citado, La Biblia Políglota de Amberes en la correspondencia de Benito Arias Montano (Ms. Estoc. A 902), pp. LII-LIV.

${ }^{19}$ Véase la carta de B. Ruiz de Ávila de 8 de junio de 1595. 
Rey y con su secretario Gabriel de Zayas ${ }^{20}$, los informes enviados a la corte sobre la difícil situación de Flandes ${ }^{21}$, sus gestiones en Lisboa y Roma sobre el problema sucesorio de Portugal. Lo cierto es que Montano teje a lo largo y ancho de toda Europa una red de contactos e informadores, que se despliega por encima de las fronteras, y que es utilizada con fines de diplomacia secreta. Relaciones que sin duda se vieron favorecidas por su familia adoptiva, pues Montano está muy unido a dos familias de mercaderes conversos afincadas en Sevilla, los Núñez Pérez y los Vélez Alcocer, con intereses en el Nuevo Mundo y en los principales puertos de Europa ${ }^{22}$.

Por la fecha de las misivas podemos colegir casi con total seguridad que el frexnense las recibiría en Sevilla, donde aprovecha sus años de priorato para enfrascarse en la redacción de su opus magnum ${ }^{23}$ y concluir los Comentarios al Profeta Isaías ${ }^{24}$. A finales de 1592 Arias Montano había sido nombrado prior del convento de Santiago de la Espada de Sevilla, cargo que desempeñó hasta finales de 1595, según sabemos de forma indirecta gracias al testimonio de Pedro de Valencia, quien el 7 de diciembre de 1595 le escribe a fray José de Sigüenza lo siguiente: "Arias Montano cumplió con su officio de prior boníssimamente, bendito Dios; está con salud y contento, libre de aquella occupación, en su Campo de Flores, donde prosigue a buen passo su obra grande» ${ }^{25}$. No obstante, Montano

20 Marqueses de PidAl y de Miraflores (1862). «Correspondencia del Dr. Benito Arias Montano con Felipe II, el secretario Zayas y otros sugetos desde 1568 hasta 1580». Colección de documentos inéditos para la Historia de España. Madrid: Imprenta de la viuda de Calero, t. XLI, pp.127-418.

${ }^{21}$ L. Morales Oliver (1927). Arias Montano y la política de Felipe II en Flandes. Madrid: Voluntad.

22 Cf. J. Gil (1998). Arias Montano en su entorno. [Bienes y herederos]. Mérida: Editora Regional de Extremadura, pp. 103-140.

${ }^{23}$ El Opus magnum, como la designó Pedro de Valencia, es la obra que sintetiza el pensamiento de Montano desde su madurez intelectual y desde la paz espiritual. En ella expone su concepción de Dios, del mundo y del hombre. La obra, que consta de varias partes, es un resumen de su pensamiento teológico, filosófico y científico. La primera parte, que lleva por título Liber generationis et regenerationis Adam siue de Historia generis humani; operis magni prima pars, id est, Anima, se publicó en Amberes en 1593, y encierra una síntesis de la salvación del género humano, de la generación del hombre viejo en Adán, y de la regeneración del hombre nuevo en Jesucristo. De la segunda parte sólo conservamos la titulada Naturae Historia, que se publicó póstuma en 1601. En ella se analiza desde un punto de vista filosófico y científico la historia de la creación del universo y del hombre. Se ha perdido por completo la parte titulada Vestis.

${ }^{24}$ B. ARIAE Montani (1599). Commentaria in Isaiae prophetae sermones. Amberes: El compás de oro.

${ }^{25}$ G. Antolín (1896). «Cartas inéditas de Pedro de Valencia al P. José de Sigüenza». La Ciudad de Dios, XLI, p. 495. 
siguió interviniendo en la dirección de aquella comunidad tras dejar las obligaciones del priorato ${ }^{26}$; por lo que no es de extrañar que todavía en junio de 1596 Bartolomé Ruiz de Ávila siga dirigiéndose a él como prior de Santiago de los Caballeros de Sevilla.

Respecto a los criterios seguidos en la edición de los documentos debemos advertir que las cartas van precedidas de un encabezamiento donde se recogen los nombres del remitente y del destinatario, seguidos entre paréntesis del lugar donde se redacta y donde se recibe la carta. En una segunda línea indicamos, a la izquierda, la localización de los originales dentro del manuscrito A 902 de la Biblioteca Real de Estocolmo (nos referimos a él de forma abreviada como Ms. Estoc.); y, a la derecha, la fecha del escrito.

Los textos se han transcrito manteniendo como norma general los usos gráficos de Ruiz de Ávila y de Arias Montano. Así las grafías $b$ y $v$ hemos procurado mantenerlas como aparecen escritas. La nasal $n$ se ha mantenido ante consonantes labiales tal y como sistemáticamente la escribe Ruiz de Ávila (sienpre, tienpos,...). Las elisiones vocálicas se han señalado con el correspondiente apóstrofo (d'él, d'estas, d'ellos, d'Ávila, ...). Sin embargo, y a fin de facilitar la lectura y comprensión de los textos originales, se han introducido algunos arreglos que hemos considerado oportunos. En este sentido hemos desarrollado entre corchetes las grafías omitidas en la mayoría de las abreviaturas, con la salvedad de las consonantes $m$ y $n$ (la rayita que las representa en los textos manuscritos se ha sustituido por la nasal correspondiente) y de la conjunción que (dada la frecuencia de esta conjunción la desarrollamos directamente sin ninguna indicación que dificulte la lectura del texto). Hemos recogido con criterios actuales, según aparezcan en posición inicial o en interior de palabra, las vibrantes múltiples que Ruiz de Ávila, siguiendo una práctica muy generalizada en su tiempo, anota con $R$ mayúscula (así ahoRen lo transformamos en ahorren y Remedio en remedio). Así mismo, la puntuación, el uso de las mayúsculas y la acentuación se han modernizado de acuerdo con las exigencias filológicas actuales; en algunos casos incluso hemos colocado tilde sobre la $y$ para evitar ambigüedades. Hemos recogido en notas a pie de página, las aclaraciones que hemos considerado necesarias para la

${ }^{26}$ G. Morocho (1999). «Trayectoria humanística de Benito Arias Montano. II. Años de plenitud (1568-1598)». En MARQUÉS DE LA ENCOMIENDA y otros (eds). El Humanismo extremeño. Estudios presentados a las $3^{a s}$. Jornadas organizadas por la Real Academia de Extremadura. Trujillo: Real Academia de Extremadura de las Letras y las Artes, p. 293, dice que «después de haber cesado, sabemos que Arias Montano siguió interviniendo en el gobierno de aquella casa por mandato expreso de Felipe II», y cita en nota varios documentos del Archivo Histórico Nacional, Sección de Órdenes Militares. 
correcta comprensión de las cartas. En cambio, las aclaraciones introducidas dentro del cuerpo del texto aparecen entre corchetes y con letra cursiva para que se diferencie perfectamente que se trata de adiciones nuestras; por ejemplo, [Sobrescrito:].

Los únicos signos diacríticos utilizados en los textos son los siguientes:

$<>$ indica la adición de palabras suplidas por estar dañado el original.

[ ] indica letras restauradas en el desarrollo de las abreviaturas.

| indica final de recto.

\| indica final de folio. 


\section{Documentos}

\section{Bartolomé Ruiz de Ávila (Hinojos) a Benito Arias Montano (Sevilla) O: Ms. Estoc. ff. 220-221. 8 VI 1595}

Por aver estado ausente d'este lugar, muchos días a no he escrito a v[uestra] $\mathrm{m}$ [erced]. Y casi estava determinado de no hazerlo aora sobre este caso, por parecerme que tampoco an de tener enmienda los daños presentes como la an tenido los passados de que he advertido. Mas considerando que los tienpos y las ocasiones no son sienpre unos, no quise dexarlo de hazer por no quedar con este escrúpulo para que d'él resultase algún nuevo cargo a mi conciencia, por la qual juro a v[uestra] $\mathrm{m}$ [erced] y le certifico que de todo lo que escrivo de los ministros de la casa del cardenal $^{27}$ y de las pocas limosnas que en ella se hazen y grandes

${ }^{27}$ Rodrigo de Castro Osorio, (Valladolid 5 de marzo de 1523 - Sevilla 1600) fue cardenal, obispo de Zamora, (1574-1578) y de la diócesis de Cuenca, (1578-1581), arzobispo de Sevilla (1581-1600), miembro del Consejo de Estado de España y del Supremo Consejo de la Inquisición durante el reinado de Felipe II. Tío-abuelo de Pedro Fernández de Castro y Andrade, séptimo conde de Lemos; estrechamente vinculado a la ciudad gallega de Monforte de Lemos, donde fundó el Colegio de Nuestra Señora de La Antigua. Conocido popularmente como "Cardenal Rodrigo de Castro», auténtico hombre renacentista, considerado por muchos autores como el último gran príncipe eclesiástico; su lugar de nacimiento es disputado, ya que no se ha podido encontrar la partida de nacimiento; sin embargo, algunos autores sostienen que nació en Valladolid en 1523, por encontrarse allí circunstancialmente su madre, Beatriz de Castro, la tercera condesa de Lemos. Estudia derecho canónico en Salamanca, donde es obispo su hermano Pedro de Castro Lemos (20 de febrero de 1545 5 de junio de 1553), que sería más tarde obispo de Cuenca (1553-1561). Acompañó al Rey en la jornada de Inglaterra, llevándolo consigo don Pedro de Castro, su hermano, obispo de Salamanca, que iba por capellán mayor; de Londres pasó a Roma en compañía del marqués de Sarria, su deudo, quedando como embajador en aquella Corte, donde siempre fue grato al Pontífice Paulo V. Volvió a Flandes el año de 1556, haciendo grandes servicios al Rey, que le granjearon crédito de ministro importante. Vuelto a España en 1559, entró a formar parte del Consejo de Estado y del Supremo Consejo de la Inquisición, donde se ocupó de la prisión del arzobispo de Toledo don fray Bartolomé de Carranza y Miranda, sobre cuyos negocios fue por segunda vez a Roma. Finalmente, después de haber hecho mérito en grandes negocios, fue presentado obispo de Zamora el año de 1573, y promovido en el de 1576 a Cuenca, donde este año recibió carta del Rey, que le mandaba pasar a Barcelona a recibir a la Emperatriz doña María, su hermana, que venía de Alemania; partió a 24 de agosto, y al mismo tiempo de salir tuvo aviso de su presentación a la Iglesia de Sevilla en carta del secretario Mateo Vázquez de Leca. Acompañó a la Emperatriz desde Barcelona al Escorial, desde allí a Lisboa, donde se hallaba el Rey. Ya en el año de 1582, a 15 de febrero tomó posesión de la sede vacante de Sevilla en la persona del Licenciado Iñigo de Lisiñana, que quedó por su provisor, habiéndose pasado en Roma sus Bulas a 20 de septiembre del año anterior. Es nombrado cardenal el 15 de diciembre de 1583, por Gregorio XIII. Es muy criticado por su gusto por el boato y la suntuosidad. Se suceden costosas partidas de caza, y gran número de sirvientes y criados, además del gusto por el lujo y las obras de arte, muchas de las cuales ha ido atesorando en sus diferentes viajes. Siente una gran afición por la cetrería, de la cual queda constancia por el Tratado de la caza de las 
robos en aquellos tribunales del provisor $^{28}$ y juez de la Yglesia, y de todo lo más del memorial que va con esto, que soy buen testigo y lo pudiera ser mejor si de hordinario asistiera en Sevilla. Y que así mismo las hordenaças y premáticas que aý van apuntadas no sirven de más que de tronpeçones para que los juezes y sus ministros hagan causas y lleven penas a muchos sin aver cometido culpas; porque si Su Mag[esta]d no quiere que jueguen a los naypes, con mandar que no se hagan estava acabado ${ }^{29}$; y si tampoco no es servido que aya caça, mande que no aya

aves de Pero López de Ayala, que aún se conserva en el museo de Nuestra Señora de la Antigua, y que pertenecía a su colección personal. Surgen asimismo críticas en su arzobispado de Sevilla al rodearse exclusivamente de sirvientes y colaboradores gallegos. En contrapartida destaca su generosidad y humanismo; crea una residencia para chicas en situación difícil, lucha por la humanización del trato en las prisiones, ayuda al clero empobrecido y ayuda a la construcción y mejora de templos, hospitales y asilos, además de ejercer de mecenas de las artes. (A. CotARELO Vallador (1945). El Cardenal Don Rodrigo de Castro. Madrid: Editorial Magisterio Español. D. ORTIZ DE ZÚÑIGA (1796). Anales eclesiásticos y seculares de la muy noble y muy leal ciudad de Sevilla. Madrid: Imprenta Real, libro XV, pp. 124-125).

${ }^{28}$ El licenciado Iñigo de Lisiñana (o Lesiñana), provisor y vicario general de la archidiócesis de Sevilla por el cardenal arzobispo D. Rodrigo de Castro.

${ }^{29}$ Los juegos de apuestas estaban prohibidos por diversas pragmáticas reales, ya que solían originar disputas entre los jugadores, por esto no es de extrañar que ya desde la Edad Media, los gobernantes se preocuparan de castigar a los que infringían las leyes sobre este particular. Los más prohibidos eran los dados y los naipes, lógicamente los más populares y de mayores apuestas. Resultaba difícil aplicar las restricciones a los juegos, y los visitadores eran informados de continuos desacatos a las normativas reales. La Ley de Juan I dada en Bribiesca en 1387, y confirmada más tarde por los Reyes Católicos en Madrigal en 1476, prohibía jugar a los dados y a los naipes y estipulaba las penas consiguientes: «Mandamos y ordenamos que ningunos de los nuestros reynos sean osados de jugar dados ni naypes en público ni en escondido; y qualquier que los jugare, por la primera vez pague seiscientos maravedís, y por la segunda mil y doscientos maravedís, y por la tercera mil y ochocientos maravedís, y dende en adelante por cada vez tres mil maravedís; y si no hobiere de que los pagar, que yagan por la primera vez diez días en la cadena, y por la segunda veinte días, y por la tercera treinta días, y así dende en adelante por cada vez, no teniendo de que pagar los dichos maravedís, esté preso treinta días. Y mandamos que aquel que alguna cosa perdiere, que lo pueda demandar a quien se lo ganare hasta ocho días, y el que lo ganare sea tenido de tornar lo que así ganare; y si el que perdiere hasta ocho días no lo demandare, que qualquier que se lo demandare lo haya para sí; y si alguno no lo acusare ni demandare, que qualquier juez o alcalde de su oficio, sabiéndolo, lo execute, y sea para la nuestra Cámara; y si así no lo hiciere el juez, pague seiscientos maravedís, la mitad para el que lo acusare, y la otra mitad para la Cámara». (Novísima Recopilación de las Leyes de España. Madrid, 1805, Libro XII, tit. XXIII, ley I, pág. 402). No sólo se contentaron los reyes con prohibir el juego, sino que por las leyes promulgadas por la reina $\mathrm{D}^{\mathrm{a}}$ Juana y Don Fernando el Católico en Burgos, en 1515, y más tarde por Carlos I en 1523 y 1537, se prohibió la fabricación y venta de los dados en todo el reino. Felipe II siguió con la misma política que los reyes anteriores en este tema, así en 2 de febrero de 1568 promulgó una ley en Madrid por la que se imponían nuevas penas a los que hicieren, tengan o jueguen dados. El 18 de febrero de 1575 aumentó dichas penas a los aprehendidos en juegos prohibidos, con extensión al de la cartera. Y en las pragmáticas dadas en Montemor a 20 de febrero de 1586, y en Aranjuez a 9 de mayo de 1593, hizo 
postura $^{30}$ en ella, sino que se castigue a quien la matare; y cesando estas causas cesarán los daños que hazen sus efetos. Mas si es justa cosa que la aya, pues para el sustento del hombre la crió Dios, tanbién es justo que no se le lleve pena a quien la matare de qualquier suerte que sea ${ }^{31}$. Y si todo esto que escrivo fuere necesario que se averigüe, yo diré el cómo quando convenga; aunque cosas tan comunes y tan ciertas como aquestas, ellas propias se dexan entender y traer la verdadera averiguación consigo, sin que sea menester hazer otra nynguna. Suplico a v[uestra] $\mathrm{m}$ [erced] ponga ese memorial en las manos de quien lo $\mid$ remedie, como lo a hecho de los demás que yo he enbiado, que puesta intercesión de los buenos puede mucho con Dios, tanbién podrá con los reyes; que no es posible que persuadiéndolo muchas vezes dexe de remediarlo, y de hazer v[uestra] $\mathrm{m}$ [erced] cómo se me enbíe una certificación de la cantidad de los salarios que llevan por año los comisarios de los proveedores de las armadas y fronteras, porque podía ser que dé yo horden cómo se ahorren y no los lleven, y se escusen las pesadunbres que dan en todos los lugares adonde van; y que aquesta venga con la razón por qué manda $\mathrm{Su}$ Mag[esta]d que se visiten las flotas que vienen de Indias, y qué provecho se saca

extensivas las penas aplicables a los jugadores de dados al juego de los naypes que llaman los bueltos, bolillo, trompico, palo y otros. Aunque naipes y dados suelen correr la misma suerte, y las prohibiciones relativas a los dados suelen hacerse extensivas a los naipes, llama la atención que se hubiese vedado la fábrica y venta de dados, y en cambio no se hubiera hecho otro tanto con los naipes, tal y como denuncia Bartolomé Ruiz de Ávila. Sabemos por las actas de visita que, a pesar de las recomendaciones dictadas por los visitadores a las villas y lugares, se seguía jugando a los naipes y otros juegos vedados.

${ }^{30} \mathrm{Se}$ llama postura al precio que por la justicia se pone a las cosas comestibles. (Diccionario de Autoridades). Ese precio unas veces lo fijaba la corona y otras, los concejos.

${ }^{31}$ La pragmática dada en Madrid el 11 de marzo de 1552 por Carlos I y por el Príncipe Felipe establecía en el capítulo primero la prohibición de cazar en los tiempos de cría: «Mandamos y prohibimos que en tiempo de cria no se pueda cazar ningún género de caza; lo qual declaramos que sea en los meses de marzo, abril y mayo de cada un año más o menos, según durare el tiempo de la cría en cada tierra o provincia; so pena que si alguna persona o personas, de qualquier estado y condición que sea, cazare o tomare huevos en el dicho tiempo, caya e incurra en pena de dos mil maravedís, y sea desterrado del lugar do fuere vecino por tiempo de medio año, y pierda los aparejos que llevare; y la tercia parte de la dicha pena sea para el denunciador, la otra para el juez que lo sentenciare, la otra para nuestra Cámara». En el capítulo tercero se establecía la prohibición de cazar con tiro de pólvora y con yerba de ballestero «so pena que el que lo contrario hiciere incurra en pena de diez mil maravedís, y que sea desterrado del lugar donde viviere, con cinco leguas alrededor, por espacio de un año, y por la segunda vez sea doblada la pena del dinero y destierro». Y en los capítulos cuarto y quinto se fijaba la prohibición de «cazar con lazos de arambre, ni con cerdas ni con redes, ni con otro género de instrumento; ni con reclamos ni bueyes; ni con perros mocharniegos, so pena de seis mil maravedís; y que sea desterrada la persona que lo contrario hiciere por medio año del lugar donde fuere vecino. Y que no puedan tener ni tengan perdigones para cazar, ni los tengan en sus casas, so pena de tres mil maravedís, y que le maten el perdigón». (Novísima Recopilación de las Leyes de España. Madrid, 1805, Libro VII, tit. XXX, leyes II-IV, pp. 639-640). 
d'estas visitas, y qué daño se siguiría si no se hiziesen. Porque quiero ver si le puedo servir en aprovechalle su hazienda tan bien como en advertir de los daños que se hazen en su reyno; porque, ya que le sirvo en lo uno, le quiero servir en todo sin que se ofenda Dios ni la República. Que si no acertare a salir con el intento que llevo, recebiese a mi buen deseo; que más haré yo en pensar cómo tenga buen fin lo que escriviere que hará Su Magestad y sus consejeros en echallo por aý si no les contentare, quanto más que primero tomarán mis papeles puerto en las manos de $\mathrm{v}$ [uestra] $\mathrm{m}$ [erced], para que los correga ${ }^{32}$, que pasen adelante donde se pierdan y no se reciban con tan buena voluntad como se escriven y se enbían.

Y pida v[uestra] $\mathrm{m}$ [erced] a las bueltas d'esto que se me haga la $\mathrm{m}$ [erce]d que tengo suplicada en enbiarme la provisión para no poder ser preso por deudas por seis años, ni que mis bienes sean enbargados ni sacrestados ${ }^{33}$ durante este dicho tienpo, sino que libremente pueda gozar d'ellos, para que teniendo esta siguridad esté mejor en lo que escriviere y pueda con más conmodidad pagar lo que deviere, sin que lo que vale dies ${ }^{34}$ me lo tomen por quatro, que yo haré servicios a $\mathrm{Su}$ Mag[esta]d, si bivo, que merescan más $\mathrm{m}[$ erce]d de la que en esto se me hiziere. Guarde Dios a v[uestra] m[erced]. De Inojos y junio a 8 de 1595 años.

\section{Bar[tolom]é Ruiz d'Ávila. \| \\ [Anotaciones de Arias Montano: $]^{35}$}

Los naypes: condénanse los de la cartilla en $50 \mathrm{~m}$ [a]r[avedíe]s y los de más juego en 600 . Y permíttense los naypes y hay estanco ${ }^{36}$ d'ellos.

\footnotetext{
32 Entiéndase: corrija.
}

${ }^{33}$ Entiéndase: secuestrados. El secuestro, explica el Diccionario de Autoridades, era el depósito judicial que se hacía en un tercero de alguna alhaja o bien en litigio hasta decidir a quién pertenecía.

34 Posible efecto del seseo, fenómeno que ya en esta fecha triunfaba en Andalucía causando verdaderos estragos.

35 Esas anotaciones de Arias Montano, tomadas del memorial que Ruiz de Ávila le envía junto con esta carta, constituyen un testimonio de notable interés para conocer los abusos de las autoridades civiles y religiosas en la época. Además tienen el valor añadido de la libertad y franqueza con las que tales abusos son denunciados por este confidente de Montano, lo que nos permite suponer que no sería la primera vez que remitía informes de esta naturaleza y que el de Fregenal se sirve de ellos para mantener informados a los secretarios de Estado e incluso al propio Rey.

${ }^{36}$ Según el Diccionario de Autoridades, se llama estanco el asiento que se hace para acotar la venta de las mercancías y otros géneros vendibles, poniendo tasa y precio a que fijamente se hayan de vender, y embarazando que otros puedan tratar y contratar en los géneros que uno toma por su cuenta, y por cuyos derechos y rentas hace escritura y obligación, como sucede en el tabaco, naipes, nieve y otras especies y géneros; y así se dice del que hace semejante postura y asiento que estanca o hace estanco de tal o tal cosa. 
$\checkmark$ Que no se cacen perdizes ni conejos en ciertos t[iem]pos. Y hay postura de la caça y penan a los caçadores o los roban los juezes, y son pobríssima gente.

$\checkmark$ Que van para cada negocio un veintiquatro y un jurado a corte por darles en que ganar y gran costa a la ciudad y erario. Y tienen también procurador general de assunto en corte y letrados y solicitadores salariados. $\mathrm{Y}$ es occasión de no pagarse los tributos y otras deudas de la ciudad.

$\checkmark$ Que se tome cuenta de la imposición que se echa en la ciudad y en los otros lugares, y no se dé lic[enci]a en más quantidad ni por más t[iem]po de lo que bastare para la necessidad que se offreciere.

$\checkmark$ Que se mande a los prelados que no lleven derechos de collaciones, de capellanías, ni prebendas, ni de repartimi[ent]o de predicadores a los pueblos, ni de repartim[ient]o de missas, ni de las causas que ante ellos passaren, pues llevan salarios sus oficiales; y donde no los llevan, se los manden dar. Véndese por dineros lo que se deve dar gratis, y dasse mal despacho a los negociantes por sacarles dineros y más y más costas.

$\checkmark$ Vende el Arçob[is]po los alguaziles de los lugares y les da facultad para que denuncien y prendan los que quebrantan las fiestas. Los alguaziles, por tener de qué pagar y ganancia, dan lic[enci]as para trabajar tales días. Iten usurpan la jurisdición real condennando a seglares en semejantes penas. Que si tienen facultad para ello, no vendan los officios; que hazen notarios hombres inhábiles, y arriendan los officios por mucho dinero.

$\checkmark$ Que los juezes ecclesiásticos y seglares se encuentran en causas y las sentencian y condennan por ambas partes. Que pues la just[ici]a seglar no conoce de los ecclesiásticos, que no los consientan conocer de $\operatorname{los}^{37}$ seglares.|

[Sobrescrito:] Al doctor Arias Montano del Concejo del Rey ${ }^{38}$ N[uest]ro Señor y prior de Santiago de los Cavalleros de Sevilla. Sevilla.

\footnotetext{
${ }^{37}$ Repetido: de los.

38 Aunque la opinión de Arias Montano es solicitada por el monarca en numerosos asuntos de gran interés para la Corona, nunca desempeñó un cargo político ni formó parte del Consejo de Estado.
} 


\section{Bartolomé Ruiz de Ávila (Hinojos) a Benito Arias Montano (Sevilla) \\ O: Ms. Estoc. ff. 222-223. \\ 31 VII 1596}

Estará ya v[uestra] $\mathrm{m}$ [erced] tan enfadado de oír nuevas del triste çubceso de las ciudades de Cadis y Faro ${ }^{39}$, que se pudiera tener por cosa escusada el referillas, pues el tratar de las causas de estos daños y del remedio de los por venir tanbién lo sería, porque sólo sirven estos avisos, y otros no menos importantes que ellos, de gastar el tienpo y cansar los entendimientos sin aprovechar de nada. A cuya causa estava determinado de poner todo lo que supiese en el libro del olvido, donde deve de estar todo lo demás que v[uestra] $\mathrm{m}$ [erced] a escrito y encargado que se hiziese, pues ninguna cosa de todas ellas, siendo tan justa, a salido a lus, ni creo que por serlo se puede tener esperança que saldrá; porque los por cuya mano pasan estas cosas, deven de poner deficultades en ellas para que todo ande a ciegas y que no se vea este abismo de adonde salen siempre n[uest]ros daños; los quales van cada día en tanto crecimiento que por governarse los que estavan en Cadis por cabeças que quieren ser universales en todo, no siendo particulares en su facultad, se perdió y se perderá todo el mundo, si Su Mag[esta]d no pone ministros de esperiencia ${ }^{40}$ que lo defiendan, porque las leyes y ordenanças de la milicia no se leen ni enseñan en Salamanca, sino en Ytalia, Flandes y otras partes donde Su Mag[esta]d tiene

39 Tras abandonar Cádiz, los mandos ingleses reunidos el viernes 19 de julio a bordo del Ark Royal acordaron hacer un desembarco en Ayamonte y correr luego la costa hasta la ciudad de Faro. Sin embargo, el día 20, por miedo a verse encerrados si alguna fuerza actuaba en Ayamonte, mudaron de parecer y decidieron desembarcar directamente en Faro. Esta maniobra no la llevaron a cabo hasta el día 23, y a las doce del día siguiente entraron las primeras tropas en Faro, encontrándose la ciudad sin moradores. El día 25, al despuntar el alba, un destacamento de 600 soldados a las órdenes de Sir George Carew recorrió la costa arrasando e incendiando cuanto encontraban a su paso. El día 26, la ciudad de Faro fue incendiada hasta los cimientos, y al día siguiente, antes de las cuatro de la tarde, habían reembarcado todas las tropas. El domingo 28, aprovechando el viento favorable, la flota angloholandesa se dio a la vela. (Cf. F. PONCE CORDONES (1997). «El ataque a Cádiz en 1596, según el diario del Mary Rose». En M. Bustos RodríGuez (dir.). El asalto anglo-holandés a Cádiz en 1596 y su contexto internacional. Cádiz: Servicio de Publicaciones de la Universidad de Cádiz, pp. 33-55).

40 Posible alusión a don Alonso Pérez de Guzmán (1550-1619), séptimo duque de Medina Sidonia y décimo conde de Niebla, quien por su lentitud y timidez en socorrer la ciudad de Cádiz se convirtió en el blanco de las iras de toda la población. Tras la muerte repentina del marqués de Santa Cruz en febrero de 1588, Felipe II insistió en ponerlo al frente de la Armada Invencible. A pesar del desastre de la empresa, el duque de Medina no sólo conservó el favor real, sino que fue nombrado Capitán general del Mar Océano, y de la costa de Andalucía, y de la Armada y Ejército de Su Majestad. Sin embargo, en opinión de los oficiales y soldados perdió la honra, reputación y fama de España y la de su persona y casa, teniendo cobardía y continuo pavor y miedo a morir; y así fue menospreciado de todos. Aunque tampoco demostró gran pericia con ocasión del nuevo revés que para la reorganización de la flota supuso el saqueo de Cádiz, el duque siguió controlando las cuestiones relacionadas con la Armada Real. 
$\operatorname{presidios}^{41}$; y así no ay para qué nombrar personas para que goviernen y asistan | en estas fronteras y puertos de mar que no sean graduadas por estas universidades que tengo dicho. Ni tanpoco se deve aconcejar a Su Mag[esta]d que ponga estanco en la pólvora y demás municiones por cudicia de quatro reales, que aquestos le hazen muy poco al caso; porque de estas cosas y otras semegantes deven de servir algunos de los que aconcejan, por parecerles que aquellos solos sirven bien a $\mathrm{Su}$ Mag[esta]d, que le dan materia de adonde saque dineros, siendo como es en este caso el camino más llano que puede aver para perdellos; porque de aver estanco viene a estar falto de municiones este reyno, y a ponerse en condición de perder una buena parte de esta Andaluzía, como sin duda se perdiera si el inglés fuera discreto y hombre de ánimo, porque antes que acudiera socorro, pudiera tomar la flota y a Gibraltar y al Puerto y a Xerez y Sanlúcar y Rota y Puerto Real como tomó Cadis; y aun es opinión mía y de otros muchos que vimos el armada y nos hallamos presentes a todos los rebatos que después de tomado Cadis se dieron, que pudiera llegar a Sevilla y ponella en condición de tomar, por estar todos tan desapercebidos que no tenían armas ni municiones con que defendella ${ }^{42}$; pues enbiavan a Granada y a otras partes a buscallas. Y demás d'esto estar toda esta tierra llena de enemigos de otras naciones ${ }^{43}$, que por momentos deven de avisar de $\mathrm{n}$ [uest]ros descuidos. Y las galeras que eran las que otras vezes nos defendían y con quien se amenazava a todos los cosarios que nos venían a robar, es aora la peor cosa que tiene el mundo y de más costa y menos provecho; porque dies y nueve

41 Término militar tomado del latín que designa la guarnición de soldados que se pone en las plazas, castillos y fortalezas para guarda y custodia. (Diccionario de Autoridades).

${ }^{42}$ En cuanto se tuvieron noticias en Sevilla del ataque, el conde de Priego movilizó la ciudad para acudir en auxilio de Cádiz y estar prevenidos ante un eventual ataque. Sin embargo, según refiere el historiador local Francisco de Ariño, en Sevilla «no se halló alcabús, ni mecha, ni pólvora, ni espadas, ni armas ningunas aunque las pesaran a oro, sino fueron 400 alcabuces que la ciudad tenía en la Alhóndiga llenos de moho, que no eran de provecho sino era aderezándolos». El conde de Priego mandó sacar de la cárcel a muchos delincuentes para alistarlos como tropa hasta reunir veinticuatro compañías de Sevilla y de sus alrededores. (F. de ARIÑo (1873). Sucesos de Sevilla de 1592 a 1604. Sevilla: Imprenta de Rafael Tarascó y Lassa, pp. 34-35).

${ }^{43}$ La participación extranjera en el comercio colonial ibérico había llegado a su apogeo por estas fechas. Las colonias de mercaderes flamencos, holandeses e ingleses afincadas en los puertos de Sevilla y Cádiz no habían tenido en fechas previas grandes dificultades para burlar las restricciones operando a través de intermediarios españoles; pero precisamente a partir de la década de los ochenta esos mercaderes extranjeros comenzaron a beneficiarse de las primeras cartas de naturaleza otorgadas por Felipe II, lo que les permitirá cargar e incluso embarcarse en las flotas de las Indias. Cada vez era más frecuente la integración de navíos flamencos o hanseáticos en las flotas que hacían la travesía hacia el Nuevo Mundo. Ello propició que la tripulación de los barcos españoles fuera reclutada de forma muy cosmopolita; de manera que a finales de la centuria el número creciente de extranjeros asentados en el sur de la península era un hecho constatable. 
que se hallaron en lo de Cadis y estuvieron a la mira hasta que $\|$ el inglés se fue, no hizieron cosa que fuese de consideración, porque ni traen municiones ni remeros ni soldados; tanto que en todas ellas no se devieron de hallar dozientos hombres que pudiesen pelear, porque los unos no quieren andar en ellas porque no les pagan y los otros no se pueden conservar porque se les quita parte de las raciones que está mandado que se les dé. Y aunque todos sabemos que Su Mag[esta]d no queda a dever nada, porque todo lo paga y se le quenta al cabo, se queda entre los que goviernan y mandan. Suplico a v[uestra] $\mathrm{m}$ [erced] que de todo dé quenta a $\mathrm{Su}$ Mag[esta]d para que mande que aquesto siquiera se remedie; porque si no se haze, no nos espantemos después de que moros y ereges ${ }^{44}$ se tomen lo que queda y se apoderen en ello. Dios guarde a v[uestra] $\mathrm{m}$ [erced]. De Inojos y julio a postrero de 1596 años.

Bar[tolom]é Ruiz d'Ávila.

$[\text { Sobrescrito: }]^{45}$ Al doctor Arias Montano < del Concejo del Rey $>$ N[uest]ro $\mathrm{S}[$ eño]r y prior de $<$ Santiago de los $>$ Cavalleros. Sevilla.

${ }^{44}$ Junto a los protestantes ingleses y holandeses el turco constituía la otra gran amenaza para un imperio que se había erigido en defensor de la fe. Existía un temor obsesivo y casi generalizado acerca de los posibles contactos de la población morisca con los turcos. Si bien no todo eran temores infundados, en marzo de 1577, el Consejo Real recibió un alarmante informe respecto a que los moriscos de Valencia y Aragón se preparaban para alzarse en armas en cuanto llegara la flota turca; y pasaría todavía mucho tiempo antes de que el gobierno pudiera pensar en relajar sus defensas en el Mediterráneo. Por otro lado, Al-Mansur, que había jugado en el norte de África a dos bandas entre el imperio otomano y la monarquía católica, enseguida aprovechó la presencia inglesa en Cádiz para ofrecerle a Essex abastecimiento regular para 3000 hombres si se quedaba en la ciudad, y así de camino resarcirse de la ofensa que había supuesto la liberación de Muley Nasar en Melilla y la revuelta organizada por éste. Cf. D. TÉllez AlarCia (2000). «El papel del Norte de África en la política exterior hispana (ss. XV-XVI)». Tiempos Modernos 1. Revista electrónica de Historia Moderna. http://www.tiemposmodernos.org/tm3/index.php/tm/issue/view/1 [Consul-tado: 10-122009].

45 Las palabras entre corchetes angulares se han perdido en el original, aunque podemos reconstruirlas fácilmente gracias a la otra carta. Los sobrescritos constituían la parte más frágil en las cartas antiguas, ya que con frecuencia estaban escritos sobre una tira rasgada del mismo pliego de la misiva, y al abrir ésta se rompían y se separaban definitivamente del pliego, lo que facilitaba su extravío. 